Check for updates

Cite this: Phys. Chem. Chem. Phys., 2019, 21, 9785

Received 26th February 2019, Accepted 11th April 2019

DOI: $10.1039 / c 9 c p 01142 k$

rsc.li/pccp

\title{
Shock wave and modelling study of the dissociation pathways of $\left(\mathrm{C}_{2} \mathrm{~F}_{5}\right)_{3} \mathrm{~N} \dagger$
}

\author{
C. J. Cobos, ${ }^{a}$ K. Hintzer, ${ }^{b}$ L. Sölter, ${ }^{c}$ E. Tellbach, ${ }^{c}$ A. Thaler ${ }^{b}$ and J. Troe (iD *cd
}

\begin{abstract}
The thermal decomposition of perfluorotriethylamine, $\left(\mathrm{C}_{2} \mathrm{~F}_{5}\right)_{3} \mathrm{~N}$, was investigated in shock waves by monitoring the formation of $\mathrm{CF}_{2}$. Experiments were performed over the temperature range of 1120-1450 $\mathrm{K}$ with reactant concentrations between 100 and $1000 \mathrm{ppm}$ of $\left(\mathrm{C}_{2} \mathrm{~F}_{5}\right)_{3} \mathrm{~N}$ in the bath gas $\mathrm{Ar}$ and with [Ar] in the range of $(0.7-5.5) \times 10^{-5} \mathrm{~mol} \mathrm{~cm}{ }^{-3}$. The experiments were accompanied by quantum-chemical calculations of the energies of various dissociation paths and by rate calculations, in particular for the dissociation of $\mathrm{C}_{2} \mathrm{~F}_{5}$ via $\mathrm{C}_{2} \mathrm{~F}_{5} \rightarrow \mathrm{CF}_{3}+\mathrm{CF}_{2}$. The overall reaction can proceed in different ways, either by a sequence of successive $\mathrm{C}-\mathrm{N}$ bond ruptures followed by fast $\mathrm{C}_{2} \mathrm{~F}_{5}$ decompositions, or by a sequence of alternating $\mathrm{C}-\mathrm{C}$ and $\mathrm{C}-\mathrm{N}$ bond ruptures. A cross-over between the two pathways can also take place. At temperatures below about $1300 \mathrm{~K}$, yields of less than one $\mathrm{CF}_{2}$ per $\left(\mathrm{C}_{2} \mathrm{~F}_{5}\right)_{3} \mathrm{~N}$ decomposed were observed. On the other hand, at temperatures around $2000 \mathrm{~K}$, when besides the parent molecule, $\mathrm{CF}_{3}$ also dissociates, yields of six $\mathrm{CF}_{2}$ per $\left(\mathrm{C}_{2} \mathrm{~F}_{5}\right)_{3} \mathrm{~N}$ decomposed were measured. The rate-delaying steps of the dissociation mechanism at intermediate temperatures were suggested to be the processes $\left(\mathrm{C}_{2} \mathrm{~F}_{5}\right) \mathrm{NCF}_{2} \rightarrow\left(\mathrm{C}_{2} \mathrm{~F}_{5}\right) \mathrm{N}+\mathrm{CF}_{2}$ and $\left(\mathrm{CF}_{2}\right) \mathrm{N} \rightarrow \mathrm{N}+\mathrm{CF}_{2}$. The reduction of the $\mathrm{CF}_{2}$ yields at low temperatures was tentatively attributed to a branching of the mechanism at the level of $\left(\mathrm{C}_{2} \mathrm{~F}_{5}\right)_{2} \mathrm{NCF}_{2}$, from where the cyclic final product perfluoro- $N$-methylpyrrolidine, $\left(\mathrm{C}_{4} \mathrm{~F}_{8}\right) N \mathrm{NF}_{3}$, is formed which was identified in earlier work from the literature.
\end{abstract}

\section{Introduction}

Perfluorotriethylamine, $\left(\mathrm{C}_{2} \mathrm{~F}_{5}\right)_{3} \mathrm{~N}$, has a number of interesting properties. On the one hand, it may serve as a benign liquid reaction medium for Lewis acid-catalyzed organic reactions ${ }^{1}$ and other preparative applications. On the other hand, its structure is remarkable, being characterized by a nearly planar $\mathrm{C}_{3} \mathrm{~N}$ skeleton with CNC angles near to $120^{\circ}$. $^{2}$ This skeleton is surrounded by an "inner shell" of $\mathrm{CF}_{2}$ groups and an "outer shell" of $\mathrm{CF}_{3}$ groups. The structure of $\left(\mathrm{C}_{2} \mathrm{~F}_{5}\right)_{3} \mathrm{~N}$ has been discussed in relation to that of other fluorinated triamines such as $\left(\mathrm{CF}_{3}\right)_{3} \mathrm{~N}{ }^{3}$ $\left(\mathrm{CH}_{2} \mathrm{CF}_{3}\right)_{3} \mathrm{~N},{ }^{4}$ and $\left(\mathrm{SF}_{5}\right)_{3} \mathrm{~N} .^{5}$ Because of its favorable properties, $\left(\mathrm{C}_{2} \mathrm{~F}_{5}\right)_{3} \mathrm{~N}$ has also been considered as an alternative to environmentally more harmful halons. ${ }^{6}$ In a study of the thermal decomposition of undiluted gaseous $\left(\mathrm{C}_{2} \mathrm{~F}_{5}\right)_{3} \mathrm{~N}$ in a flow system, by employing gas chromatography (GC) and GC/mass spectrometry (MS) analyses of the final products, perfluoro- $N$-methylpyrrolidine,

\footnotetext{
${ }^{a}$ INIFTA, Facultad de Ciencias Exactas, Universidad Nacional de La Plata, Argentina

${ }^{b}$ Dyneon GmbH, Gendorf, D-84504 Burgkirchen, Germany

${ }^{c}$ Institut für Physikalische Chemie, Universität Göttingen, Tammannstr. 6, D-37077 Göttingen, Germany.E-mail: jtroe@gwdg.de

${ }^{d}$ Max-Planck-Institut für biophysikalische Chemie, Am Fassberg 11, D-37077 Göttingen, Germany

$\dagger$ Electronic supplementary information (ESI) available. See DOI: 10.1039/c9cp01142k
}

$\left(\mathrm{C}_{4} \mathrm{~F}_{8}\right) \mathrm{NCF}_{3}$, was identified. ${ }^{6}$ In order to shed more light on the elementary steps of the pyrolysis, shock wave studies of the thermal decomposition of $\left(\mathrm{C}_{2} \mathrm{~F}_{5}\right)_{3} \mathrm{~N}$ diluted in $\mathrm{Ar}$ appeared promising. As the decomposition may proceed through different pathways, however, the interpretation of the experiments had to be accompanied by quantum-chemical calculations of the energetics of the reactions involved. That is the subject of the present article.

At sufficiently high temperatures, an overall decomposition

$$
\left(\mathrm{C}_{2} \mathrm{~F}_{5}\right)_{3} \mathrm{~N} \rightarrow 3 \mathrm{C}_{2} \mathrm{~F}_{5}+\mathrm{N} \quad \Delta H_{298}^{\circ}=905 \mathrm{~kJ} \mathrm{~mol}^{-1}
$$

(with $\Delta H_{\mathrm{f}, 298}^{\circ}\left(\mathrm{C}_{2} \mathrm{~F}_{5}\right)_{3} \mathrm{~N}=-3138 \mathrm{~kJ} \mathrm{~mol}^{-1}$ from ref. 7, $\Delta H_{\mathrm{f}, 298}^{\circ}$ $\left(\mathrm{C}_{2} \mathrm{~F}_{5}\right)=-901.9 \mathrm{~kJ} \mathrm{~mol}^{-1}$ and $\Delta H_{\mathrm{f}, 298}^{\circ}(\mathrm{N})=472.7 \mathrm{~kJ} \mathrm{~mol}^{-1}$ from ref. 8; values for $298 \mathrm{~K}$ ) would be accompanied by the dissociation of $\mathrm{C}_{2} \mathrm{~F}_{5}$,, 10

$$
\mathrm{C}_{2} \mathrm{~F}_{5} \rightarrow \mathrm{CF}_{3}+\mathrm{CF}_{2} \quad \Delta H_{298}^{\circ}=243.8 \mathrm{~kJ} \mathrm{~mol}^{-1}
$$

which then could be followed by $\mathrm{CF}_{3}$ dissociation ${ }^{11,12}$

$$
\mathrm{CF}_{3} \rightarrow \mathrm{CF}_{2}+\mathrm{F} \quad \Delta H_{298}^{\circ}=355.5 \mathrm{~kJ} \mathrm{~mol}^{-1}
$$

and, finally, by $\mathrm{CF}_{2}$ dissociation

$$
\mathrm{CF}_{2} \rightarrow \mathrm{CF}+\mathrm{F} \quad \Delta H_{298}^{\circ}=517.6 \mathrm{~kJ} \mathrm{~mol}^{-1}
$$

(unless stated differently, enthalpies in this work are from ref. 8). 
In more detail, the dissociation (1) could proceed by a sequence of $\mathrm{C}-\mathrm{N}$ bond ruptures

$$
\begin{gathered}
\left(\mathrm{C}_{2} \mathrm{~F}_{5}\right)_{3} \mathrm{~N} \rightarrow\left(\mathrm{C}_{2} \mathrm{~F}_{5}\right)_{2} \mathrm{~N}+\mathrm{C}_{2} \mathrm{~F}_{5} \\
\left(\mathrm{C}_{2} \mathrm{~F}_{5}\right)_{2} \mathrm{~N} \rightarrow\left(\mathrm{C}_{2} \mathrm{~F}_{5}\right) \mathrm{N}+\mathrm{C}_{2} \mathrm{~F}_{5} \\
\left(\mathrm{C}_{2} \mathrm{~F}_{5}\right) \mathrm{N} \rightarrow \mathrm{N}+\mathrm{C}_{2} \mathrm{~F}_{5}
\end{gathered}
$$

which would be followed by $\mathrm{C}_{2} \mathrm{~F}_{5}$ dissociations (2) (and, at a slower rate, by $\mathrm{CF}_{3}$ dissociations (3)). Because of the compact structure of $\left(\mathrm{C}_{2} \mathrm{~F}_{5}\right)_{3} \mathrm{~N}$, also a dissociation sequence of alternating $\mathrm{C}-\mathrm{C}$ and $\mathrm{C}-\mathrm{N}$ bond ruptures

$$
\begin{gathered}
\left(\mathrm{C}_{2} \mathrm{~F}_{5}\right)_{3} \mathrm{~N} \rightarrow\left(\mathrm{C}_{2} \mathrm{~F}_{5}\right)_{2} \mathrm{NCF}_{2}+\mathrm{CF}_{3} \\
\left(\mathrm{C}_{2} \mathrm{~F}_{5}\right)_{2} \mathrm{NCF}_{2} \rightarrow\left(\mathrm{C}_{2} \mathrm{~F}_{5}\right)_{2} \mathrm{~N}+\mathrm{CF}_{2} \\
\left(\mathrm{C}_{2} \mathrm{~F}_{5}\right)_{2} \mathrm{~N} \rightarrow\left(\mathrm{C}_{2} \mathrm{~F}_{5}\right) \mathrm{NCF}_{2}+\mathrm{CF}_{3} \\
\left(\mathrm{C}_{2} \mathrm{~F}_{5}\right) \mathrm{NCF}_{2} \rightarrow\left(\mathrm{C}_{2} \mathrm{~F}_{5}\right) \mathrm{N}+\mathrm{CF}_{2} \\
\left(\mathrm{C}_{2} \mathrm{~F}_{5}\right) \mathrm{N} \rightarrow\left(\mathrm{CF}_{2}\right) \mathrm{N}+\mathrm{CF}_{3} \\
\left(\mathrm{CF}_{2}\right) \mathrm{N} \rightarrow \mathrm{N}+\mathrm{CF}_{2}
\end{gathered}
$$

appears possible. At the level of $\left(\mathrm{C}_{2} \mathrm{~F}_{5}\right)_{2} \mathrm{~N}$ and $\left(\mathrm{C}_{2} \mathrm{~F}_{5}\right) \mathrm{N}$ a crossover between the $\mathrm{C}-\mathrm{N}$ and the $\mathrm{C}-\mathrm{C}$ bond-breaking pathways would be possible.

$\left(\mathrm{C}_{2} \mathrm{~F}_{5}\right)_{3} \mathrm{~N}$ has a low vapour pressure which, nevertheless, allows for the preparation of gaseous reactant/Ar mixtures suitable for shock wave experiments. The progress of the decomposition then can conveniently be followed by recording time-resolved UV absorption signals from $\mathrm{CF}_{2}$ near $248 \mathrm{~nm}$ (see ref. 13 and 14 for high-temperature absorption coefficients of $\mathrm{CF}_{2}$ ). Additional observations near $200 \mathrm{~nm}$ might be considered for the detection of $\mathrm{CF}_{3}{ }^{15}$ At temperatures where $\mathrm{CF}_{2}$ becomes unstable, also absorption signals from CF might become observable. ${ }^{16}$ By analyzing absorption-time profiles, at first, the $\mathrm{CF}_{2}$ yields are of relevance. Second, the time dependence of the $\mathrm{CF}_{2}$ signals would be analyzed with respect to the sequence (5)-(7) followed by reactions (2) and (3) or the sequence (8)-(13) with the possibility of cross-over between the two pathways. Some speculations about the ultimate formation of $\left(\mathrm{C}_{4} \mathrm{~F}_{8}\right) \mathrm{NCF}_{3}$ in the present work were also made. In high temperature experiments, finally, the kinetics of $\mathrm{N} / \mathrm{F} / \mathrm{CF}_{2}$ mixtures of known composition becomes accessible.

In the following, the description of experimental results is preceded by quantum-chemical calculations which facilitate the interpretation of the recorded $\mathrm{CF}_{2}$ yields and of the time dependence of the recorded concentration profiles of $\mathrm{CF}_{2}$. As the decomposition of $\mathrm{C}_{2} \mathrm{~F}_{5}$ via reaction (2) represents an important intermediate step of the mechanism and as only controversial information on its rate is available,,$^{9,10}$ a modelling of this rate also appeared desirable.

\section{Quantum-chemical calculations of reaction energies}

The enthalpies of reactions (2) and (5)-(13) (at $0 \mathrm{~K}$ ) were determined by using a variety of DFT models, combined with a $6-311+\mathrm{G}(3 \mathrm{df})$ basis set, and using the Gaussian set of codes. ${ }^{17}$ In detail, B3LYP, ${ }^{18,19}$ M06-2X, ${ }^{20}$ BMK, ${ }^{21}$ and $\omega \mathrm{B} 97 \mathrm{X}-\mathrm{D}^{22}$ models were used. The quality of the DFT results was tested for the dissociation of $\left(\mathrm{C}_{2} \mathrm{~F}_{5}\right) \mathrm{N}$ in reactions (7) and (12) by also performing high-level $a b$ initio CBS-QB3 ${ }^{23}$ and $\mathrm{G} 4{ }^{24}$ calculations. As the agreement between the DFT and the $a b$ initio calculations for the $\left(\mathrm{C}_{2} \mathrm{~F}_{5}\right) \mathrm{N}$ dissociations appeared satisfactory, only DFT calculations were made for the dissociation of larger species. A comparison of the results obtained by using the various models is given in the ESI. $\dagger$

$\Delta H_{0}^{0}$ values obtained by the $\omega \mathrm{B} 97 \mathrm{X}-\mathrm{D}$ calculations are summarized in Table 1. Except for the dissociation of $\left(\mathrm{C}_{2} \mathrm{~F}_{5}\right) \mathrm{N} \rightarrow$ $\mathrm{CF}_{2} \mathrm{~N}+\mathrm{CF}_{3}$ where a barrier for the reverse reaction of about $20 \mathrm{~kJ} \mathrm{~mol}^{-1}$ was found, no barriers beyond $\Delta H_{0}^{\mathrm{o}}$ were observed for other reactions of the mechanism. The calculated value of $\Delta H_{0}^{\mathrm{o}}=237 \mathrm{~kJ} \mathrm{~mol}^{-1}$ for the dissociation of $\mathrm{C}_{2} \mathrm{~F}_{5}$ agreed satisfactorily with the literature value $\mathrm{e}^{8}$ of $240.2 \mathrm{~kJ} \mathrm{~mol}^{-1}$. The resulting overall reaction enthalpy of $\Delta H_{0}^{\mathrm{o}}=939 \mathrm{~kJ} \mathrm{~mol}^{-1}$ for reaction (1) (obtained from Table 1; calculated for $0 \mathrm{~K}$ ) also appeared consistent with the estimate of $\Delta H_{298}^{\mathrm{o}}=905 \mathrm{~kJ} \mathrm{~mol}^{-1}$ as given above (based on ref. 7 and 8 for $298 \mathrm{~K}$ ). The results of Table 1 are illustrated in Fig. 1. They illustrate possibilities for cross-over between the $\mathrm{C}-\mathrm{N}$ bond ruptures (5)-(7) accompanied by $\mathrm{C}_{2} \mathrm{~F}_{5}$ dissociation (2) and the pathway of alternating $\mathrm{C}-\mathrm{C}$ and $\mathrm{C}-\mathrm{N}$ bond ruptures (8)-(13).

A few pecularities in the sequence of reactions (8)-(13) should be noted: the alternation of high- and low-activation barrier steps in the sequence (8)-(13) indicates "bottle-necks" at reactions (11) and (13) which have particularly high barriers. Furthermore, while all other steps in the sequences (5)-(7) and (8)-(13) are of simple bond-fission character, reaction (12) involves a rigid activated complex. At least at intermediate temperatures this reduces the $\mathrm{CF}_{2}$ yield of the overall reaction. Only at sufficiently high temperatures, when all reactions are fast, one should obtain a yield of six $\mathrm{CF}_{2}$ per $\left(\mathrm{C}_{2} \mathrm{~F}_{5}\right)_{3} \mathrm{~N}$ decomposed. This prediction could be controlled easily in experiments under conditions where reaction (4) does not consume $\mathrm{CF}_{2}$.

Apart from the energetics of steps (5)-(7) and (8)-(13), the rate of $\mathrm{C}_{2} \mathrm{~F}_{5}$ decomposition (2) is of importance. We felt that an up-dated modelling of the falloff curves of reaction (2) was necessary. ${ }^{25,26}$ This was done with the formalism employed in

Table 1 Reaction enthalpies at $0 \mathrm{~K}$ in $\mathrm{kJ} \mathrm{mol}^{-1}$ (obtained by calculations using the $\omega \mathrm{B} 97 \mathrm{X}-\mathrm{D}$ model; ${ }^{22}$ results from other models are summarized in the ESI)

\begin{tabular}{lcr}
\hline Reaction & & $\Delta H_{0}^{\mathrm{o}}$ \\
\hline$\left(\mathrm{C}_{2} \mathrm{~F}_{5}\right)_{3} \mathrm{~N} \rightarrow\left(\mathrm{C}_{2} \mathrm{~F}_{5}\right)_{2} \mathrm{~N}+\mathrm{C}_{2} \mathrm{~F}_{5}$ & $(5)$ & 327.2 \\
$\left(\mathrm{C}_{2} \mathrm{~F}_{5}\right)_{2} \mathrm{~N} \rightarrow\left(\mathrm{C}_{2} \mathrm{~F}_{5}\right) \mathrm{N}+\mathrm{C}_{2} \mathrm{~F}_{5}$ & $(6)$ & 320.9 \\
$\left(\mathrm{C}_{2} \mathrm{~F}_{5}\right) \mathrm{N} \rightarrow \mathrm{N}+\mathrm{C}_{2} \mathrm{~F}_{5}$ & $(7)$ & 291.2 \\
$\mathrm{C}_{2} \mathrm{~F}_{5} \rightarrow \mathrm{CF}_{3}+\mathrm{CF}_{2}$ & $(2)$ & 237.2 \\
$\left(\mathrm{C}_{2} \mathrm{~F}_{5}\right)_{3} \mathrm{~N} \rightarrow\left(\mathrm{C}_{2} \mathrm{~F}_{5}\right)_{2} \mathrm{NCF}_{2}+\mathrm{CF}_{3}$ & $(8)$ & 345.6 \\
$\left(\mathrm{C}_{2} \mathrm{~F}_{5}\right)_{2} \mathrm{NCF} \mathrm{F}_{2} \rightarrow\left(\mathrm{C}_{2} \mathrm{~F}_{5}\right)_{2} \mathrm{~N}+\mathrm{CF}_{2}$ & $(9)$ & 46.0 \\
$\left(\mathrm{C}_{2} \mathrm{~F}_{5}\right)_{2} \mathrm{~N} \rightarrow\left(\mathrm{C}_{2} \mathrm{~F}_{5}\right) \mathrm{NCF}_{2}+\mathrm{CF}_{3}$ & $(10)$ & 512.5 \\
$\left(\mathrm{C}_{2} \mathrm{~F}_{5}\right) \mathrm{NCF} \rightarrow \rightarrow\left(\mathrm{C}_{2} \mathrm{~F}_{5}\right) \mathrm{N}+\mathrm{CF}_{2}$ & $(11)$ & 103.8 \\
$\left(\mathrm{C}_{2} \mathrm{~F}_{5}\right) \mathrm{N} \rightarrow \mathrm{CF}_{2} \mathrm{~N}+\mathrm{CF}_{3}$ & $(12)$ & 123.4 \\
$(\mathrm{TS} 12)$ & & 423.5 \\
$\mathrm{CF}_{2} \mathrm{~N} \rightarrow \mathrm{N}+\mathrm{CF}_{2}$ & $(13)$ &
\end{tabular}




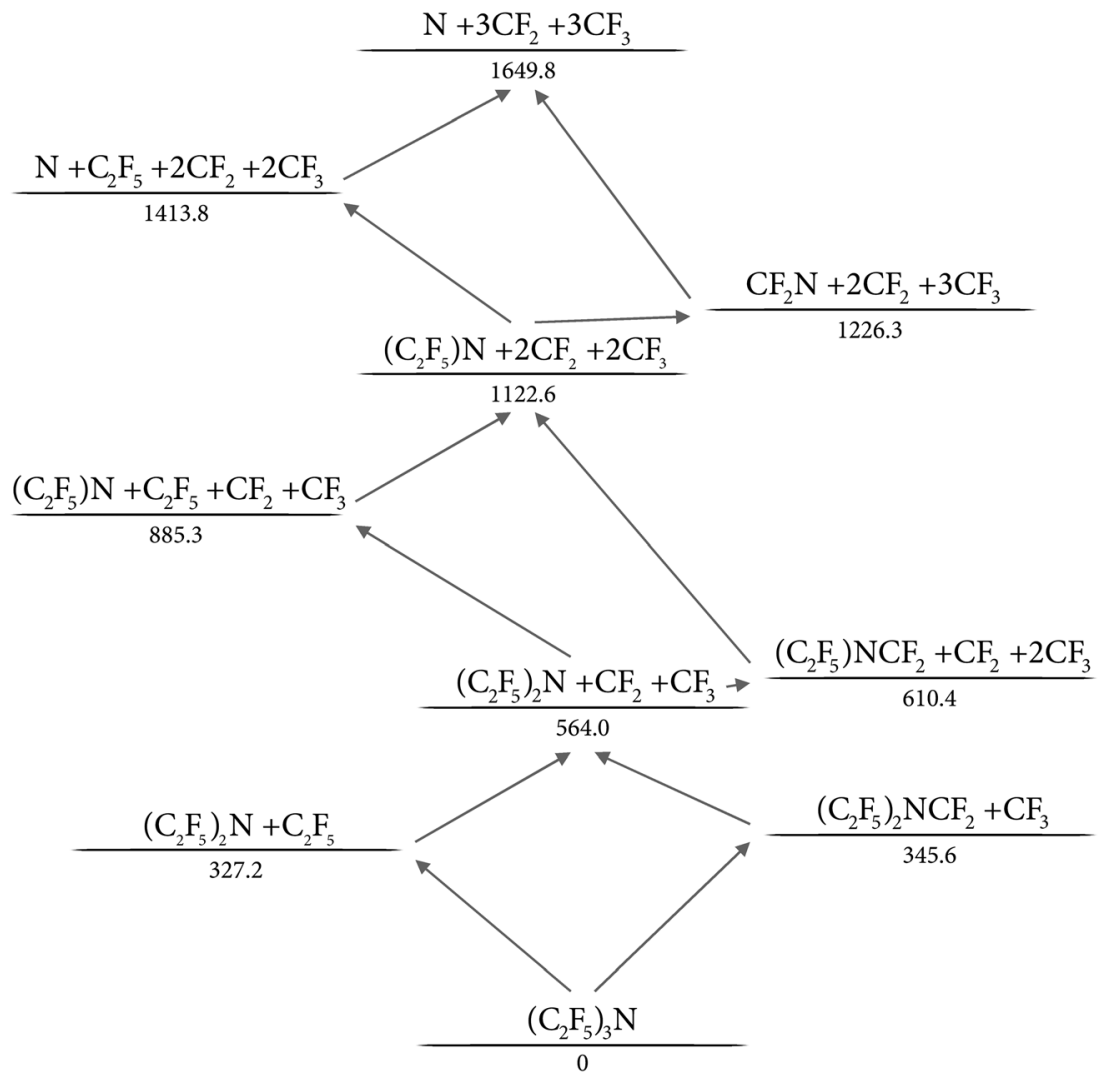

Fig. 1 Energetics of dissociation pathways (reaction enthalpies at $0 \mathrm{~K} \mathrm{in} \mathrm{kJ} \mathrm{mol}{ }^{-1}$ obtained by $\omega B 97 X-D$ calculations of the present work, see the text and the ESI $\dagger$ ).

our earlier work (see, e.g. ref. 13,15 and 16; for more details, see the ESI $\dagger$ ). The results are shown in Fig. 2. The calculation of individual rate constants for other reaction steps of the pathway was beyond the scope of the present work. Likewise, the complex rearrangement processes leading to the final cyclic product $\left(\mathrm{C}_{4} \mathrm{~F}_{8}\right) \mathrm{NCF}_{3}$ were not further investigated here.

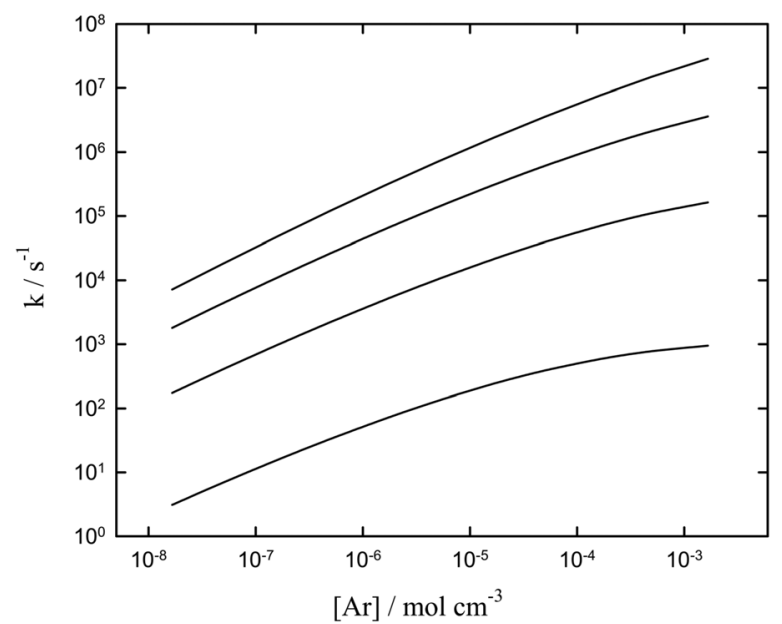

Fig. 2 Modelled falloff curves for the dissociation $\mathrm{C}_{2} \mathrm{~F}_{5} \rightarrow \mathrm{CF}_{2}+\mathrm{CF}_{3}$ (2) (pseudo-first order rate constans $k$; for details of the calculations, see the $\mathrm{ESI} \uparrow ; T=1000,1250,1500$, and $1750 \mathrm{~K}$, from bottom to top).

\section{Experimental technique and results}

Our shock wave technique has been described before (for details, see, e.g. ref. 12-16). Mixtures of $\left(\mathrm{C}_{2} \mathrm{~F}_{5}\right)_{3} \mathrm{~N}$ (from Fluorochem, purity 96\%) and $\mathrm{Ar}$ (from Air Liquide, purity 99.9999\%) were prepared in mixing vessels outside the shock tube and then introduced into the tube. Usually, low-concentration mixtures of about $200 \mathrm{ppm}$ of $\left(\mathrm{C}_{2} \mathrm{~F}_{5}\right)_{3} \mathrm{~N}$ in Ar were used, but higher concentrations (up to about $1000 \mathrm{ppm}\left(\mathrm{C}_{2} \mathrm{~F}_{5}\right)_{3} \mathrm{~N}$ ) were also employed. The experimental conditions behind incident and reflected shock waves are included in Table 2 (and given in the figure captions). UV absorption signals were recorded at selected wavelengths over the range of $200-280 \mathrm{~nm}$. The majority of the experiments were conducted at $248 \mathrm{~nm}$ where $\mathrm{CF}_{2}$ absorbs most strongly $\left(\mathrm{CF}_{2}\right.$ absorption coefficients from eqn (5) of ref. 13 were used for the determination of absolute $\mathrm{CF}_{2}$ yields during $\left(\mathrm{C}_{2} \mathrm{~F}_{5}\right)_{3} \mathrm{~N}$ decomposition).

The recorded absorption-time profiles showed a number of interesting properties. Fig. 3 gives an example. The Schlieren peak at time zero indicates the arrival of the incident shock at the observation window. At the corresponding temperature of $1371 \mathrm{~K}$, the concentration of $\mathrm{CF}_{2}$ increases up to a yield of $Y\left(\mathrm{CF}_{2}\right)=\left[\mathrm{CF}_{2}\right] /\left[\left(\mathrm{C}_{2} \mathrm{~F}_{5}\right)_{3} \mathrm{~N}\right]_{t=0}=1$. Closer inspection of the signal near time zero indicates no absorption from the parent molecule. The nature of the absorbing species $\mathrm{CF}_{2}$ could uniquely be identified by the wavelength dependence of the signal. At the 
Table 2 Apparent rate constants $k$ of eqn (16), $k_{\text {in }}$ of eqn (19), and $C F_{2}$ yields $Y$. (a) Experiments with $Y=1$ and $k_{\text {in }} \approx k$; (b) experiments with $Y<1$ and $k_{\text {in }} \approx k_{\text {; }}$ (c) experiments with $Y<1$ and $k>k_{\text {in }}$; see the text

\begin{tabular}{lllll}
\hline$T / \mathrm{K}$ & {$[\mathrm{Ar}] / 10^{-5} \mathrm{~mol} \mathrm{~cm}^{-3}$} & $k / \mathrm{s}^{-1}$ & $k_{\mathrm{in}} / \mathrm{s}^{-1}$ & $Y$ \\
\hline (a) & & & \\
1451 & 4.1 & $1.4 \times 10^{5}$ & \\
1430 & 2.7 & $6.3 \times 10^{4}$ & \\
1371 & 0.71 & $2.6 \times 10^{4}$ & \\
1367 & 4.3 & $3.4 \times 10^{4}$ & \\
1347 & 4.3 & $3.6 \times 10^{4}$ & \\
1320 & 2.2 & $1.8 \times 10^{4}$ & \\
1297 & 0.76 & $1.1 \times 10^{4}$ & \\
& & & \\
(b) & & & \\
1296 & 4.5 & $7.8 \times 10^{3}$ & \\
1246 & 4.8 & $4.9 \times 10^{3}$ & \\
1226 & 5.0 & $3.2 \times 10^{3}$ & \\
1211 & 4.9 & $2.8 \times 10^{3}$ & 0.53 \\
1160 & 5.4 & $1.5 \times 10^{3}$ & 0.39 \\
1133 & 5.5 & $1.1 \times 10^{3}$ & 0.14 \\
1130 & 5.3 & $9.0 \times 10^{2}$ & 0.09 \\
& & &
\end{tabular}

(c)

$\begin{array}{lll}(c) & & \\ 1246 & 4.8 & 1.8 \times 10^{3} \\ 1226 & 5.0 & 1.0 \times 10^{3} \\ 1196 & 5.3 & 1.2 \times 10^{2} \\ 1159 & 5.4 & 1.7 \times 10^{2} \\ 1132 & 5.3 & 6.3 \times 10^{1} \\ 1122 & 5.2 & 3.3 \times 10^{1}\end{array}$

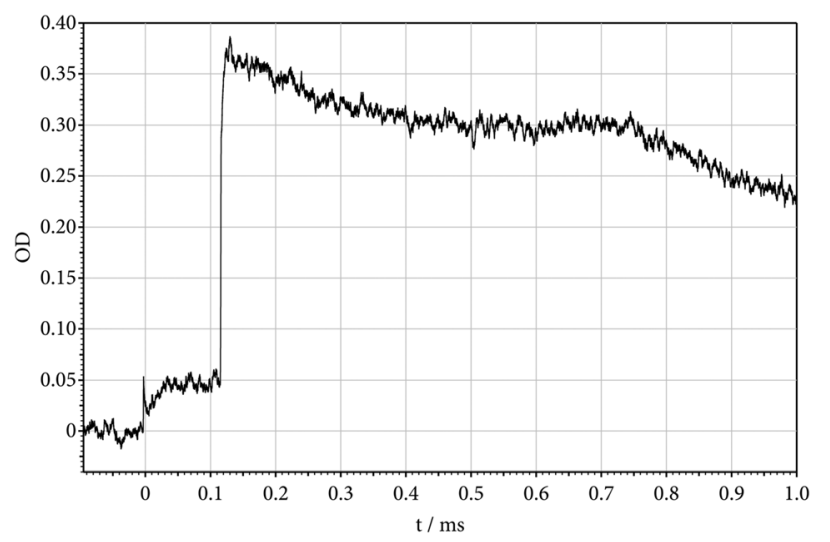

Fig. 3 Decomposition of $\left(\mathrm{C}_{2} \mathrm{~F}_{5}\right)_{3} \mathrm{~N}$ behind the incident shock wave (absorption-time profile of formed $\mathrm{CF}_{2}$ at $248 \mathrm{~nm}$; incident shock: $T=1371 \mathrm{~K},[\mathrm{Ar}]=7.1 \times 10^{-6} \mathrm{~mol} \mathrm{~cm}{ }^{-3}$; reflected shock: $T=2818 \mathrm{~K}$, $[\mathrm{Ar}]=1.6 \times 10^{-5} \mathrm{~mol} \mathrm{~cm}{ }^{-3} ; 212 \mathrm{ppm}\left(\mathrm{C}_{2} \mathrm{~F}_{5}\right)_{3} \mathrm{~N}$ in $\mathrm{Ar} ; \mathrm{OD}=\varepsilon \cdot\left[\mathrm{CF}_{2}\right] \cdot l$ with $l=9.4 \mathrm{~cm}$ and $\varepsilon=3.6 \times 10^{6} \mathrm{~cm}^{2} \mathrm{~mol}^{-1}$ for $1371 \mathrm{~K}$ and $\varepsilon=1.8 \times 10^{6} \mathrm{~cm}^{2} \mathrm{~mol}^{-1}$ for $2818 \mathrm{~K}$; instantaneous dissociation of $\mathrm{CF}_{3}$ at the time of arrival of the reflected shock, followed by the slower dissociation (4) of $\mathrm{CF}_{2}$ with $k=103 \mathrm{~s}^{-1}$ and secondary reactions, see the text).

time of arrival of the reflected shock (at $T=2818 \mathrm{~K}$ ), the absorption rises abruptly to a level corresponding to $Y\left(\mathrm{CF}_{2}\right)=6$. This value of $Y=6$ corresponds to a completion of reaction (1) followed by reactions (2)-(4) within less than $2 \mu \mathrm{s}$ (the halflife of $\mathrm{C}_{2} \mathrm{~F}_{5}$ here is about $0.025 \mu \mathrm{s}$, see Fig. 2, and the halflife of $\mathrm{CF}_{3}$ is about $1.8 \mu$ s, see ref. 12). The decrease in the absorption signal behind the reflected wave, on the one hand, reflects the dissociation of $\mathrm{CF}_{2}$ (halflife of about $700 \mu \mathrm{s}$, see ref. 12). On the other hand, there is evidence for a superimposed absorption which seems to arise from a species which has an even larger absorption coefficient than $\mathrm{CF}_{2}$. Tentatively we attribute this additional absorption to $\mathrm{CF}$, being formed by the dissociation of $\mathrm{CF}_{2}$ in reaction (4) and/or a reaction

$$
\mathrm{N}+\mathrm{CF}_{2} \rightarrow \mathrm{NF}+\mathrm{CF} \quad \Delta H_{298}^{\circ}=198.5 \mathrm{~kJ} \mathrm{~mol}^{-1}
$$

As information on further reactions like

$$
\mathrm{NF}+\mathrm{M} \rightarrow \mathrm{N}+\mathrm{F}+\mathrm{M} \quad \Delta H_{298}^{\circ}=319.1 \mathrm{~kJ} \mathrm{~mol}^{-1}
$$

( $\mathrm{M}$ denotes the bath gas) and reactions of $\left(\mathrm{CF}_{2}\right) \mathrm{N}$ is not available, an investigation of the superimposed absorption "humps" shown in Fig. 3 did not appear warranted at the present time. Because the additional absorptions appeared only at temperatures above $2000 \mathrm{~K}$, our study of $\left(\mathrm{C}_{2} \mathrm{~F}_{5}\right)_{3} \mathrm{~N}$ dissociation was not perturbed by this complication. The assumption of the presence of CF, however, did not appear improbable, because its absorption coefficient at $248 \mathrm{~nm}$ in ref. 16 was found to be about 3 times that of $\mathrm{CF}_{2}$.

The formation of $\mathrm{CF}_{2}$ was studied behind incident and reflected shock waves, as shown in Fig. 3 and 4 . The temperature of the latter experiment $(1347 \mathrm{~K})$ and the rate of formation of $\mathrm{CF}_{2}$ (accounting for the compressed time scale, behind the incident wave) were close to that of Fig. 3, while the bath gas concentrations differed markedly $\left([\mathrm{Ar}]=7.1 \times 10^{-6} \mathrm{~mol} \mathrm{~cm}^{-3}\right.$ behind the incident shock as shown in Fig. 3 and $[\mathrm{Ar}]=4.2 \times$ $10^{-5} \mathrm{~mol} \mathrm{~cm}{ }^{-3}$ behind the reflected shock as shown in Fig. 4). A pressure effect thus was not observed. The $\mathrm{CF}_{2}$ yields in both cases reached $Y \approx 1$. This changed at lower temperatures. The $\mathrm{CF}_{2}$ concentration at $1246 \mathrm{~K}$, as shown in Fig. 5, rose up to a yield of $Y \approx 0.6$ only. As Fig. 4 and 5 were obtained with the same reaction mixture (209 ppm of $\left(\mathrm{C}_{2} \mathrm{~F}_{5}\right)_{3} \mathrm{~N}$ in $\left.\mathrm{Ar}\right)$, this observation could not have been produced by concentration uncertainties (with reaction mixtures above $1000 \mathrm{ppm}$, the small $\left(\mathrm{C}_{2} \mathrm{~F}_{5}\right)_{3} \mathrm{~N}$ vapour pressure caused problems with accurate concentration determinations). Because of the limitation of the observation time behind the reflected shock to about $1 \mathrm{~ms}$, the drop of $Y$ with decreasing temperature could only be followed down to about $T \approx 1130 \mathrm{~K}$.

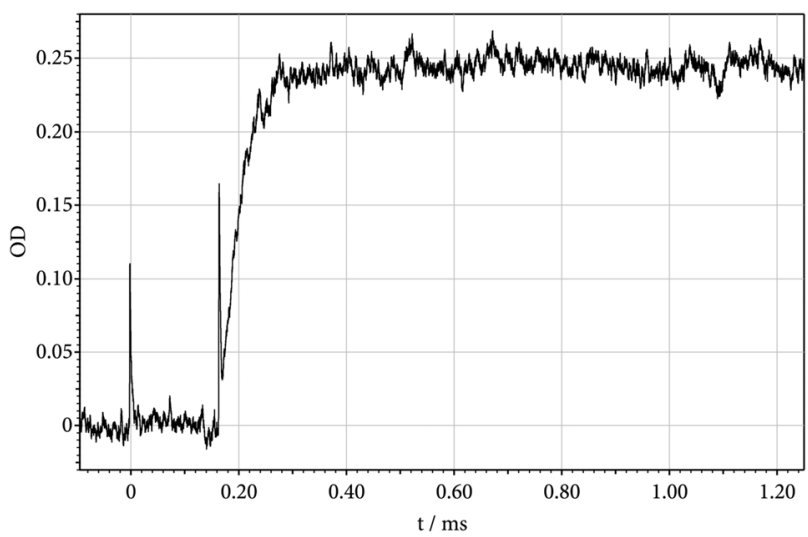

Fig. 4 Decomposition of $\left(\mathrm{C}_{2} \mathrm{~F}_{5}\right)_{3} \mathrm{~N}$ behind the reflected shock wave (absorption-time profile of formed $\mathrm{CF}_{2}$ at $248 \mathrm{~nm} ; T=1347 \mathrm{~K},[\mathrm{Ar}]=$ $4.2 \times 10^{-5} \mathrm{~mol} \mathrm{~cm}^{-3} ; 209 \mathrm{ppm}\left(\mathrm{C}_{2} \mathrm{~F}_{5}\right)_{3} \mathrm{~N}$ in $\left.\mathrm{Ar}\right)$. 


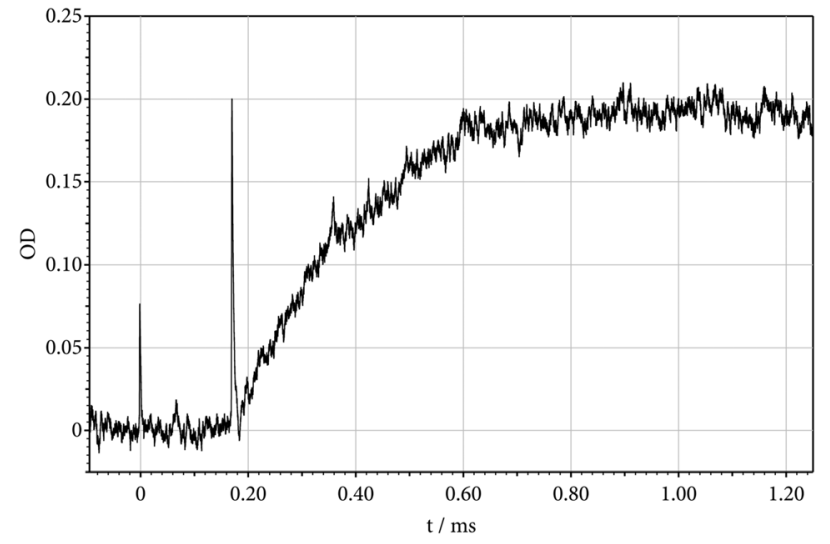

Fig. 5 The same as Fig. 4, but at lower temperature $(T=1246 \mathrm{~K},[\mathrm{Ar}]=$ $4.8 \times 10^{-5} \mathrm{~mol} \mathrm{~cm}^{-3} ; 209 \mathrm{ppm}\left(\mathrm{C}_{2} \mathrm{~F}_{5}\right)_{3} \mathrm{~N}$ in $\left.\mathrm{Ar} ; \varepsilon(1246 \mathrm{~K}) / \varepsilon(1347 \mathrm{~K}) \approx 1.15^{13}\right)$.

The recorded absorption-time profiles of $\mathrm{CF}_{2}$ were evaluated in two different ways. For the temperature range of 1130-1540 K, where a practically time-independent final $\mathrm{CF}_{2}$ yield $Y(T)$ was reached within the observation time, an effective rate law

$$
\left[\mathrm{CF}_{2}\right]_{t} /\left[\left(\mathrm{C}_{2} \mathrm{~F}_{5}\right)_{3} \mathrm{~N}\right]_{t=0} \approx Y(T)\{1-\exp (-k(T) t)\}
$$

appeared suitable. The resulting rate constants $k(T)$ and yields $Y(T)$ are summarized in Table 2 and plotted in Fig. 6 and 7, respectively. The Arrhenius representation of $k(T)$ as shown in Fig. 6 led to

$$
k(T) \approx 2.5 \times 10^{13} \exp \left(-213 \mathrm{~kJ} \mathrm{~mol}^{-1} / R T\right) \mathrm{s}^{-1}
$$

while $Y(T)$ in the form of ref. 27 was approximated by

$Y(T) \approx\left[1-\left(T-T_{\mathrm{e}}\right) /\left(T_{\mathrm{e}}-T_{\mathrm{m}}\right)\right]\left[\left(T-T_{0}\right) /\left(T_{\mathrm{e}}-T_{0}\right)\right]^{\left(T_{\mathrm{e}}-T_{0}\right) /\left(T_{\mathrm{e}}-T_{\mathrm{m}}\right)}$

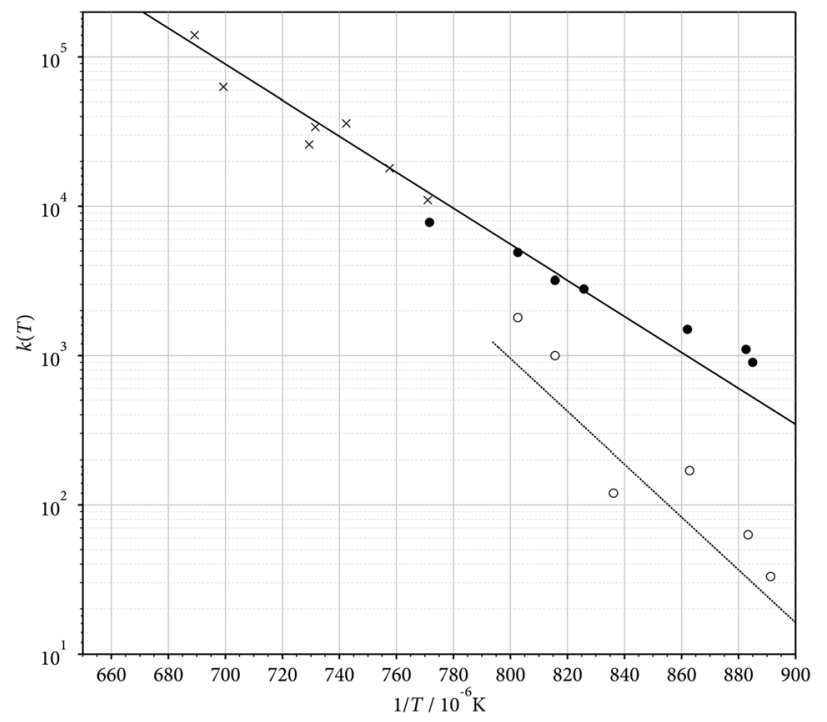

Fig. 6 Apparent rate constants $k$ of eqn (17) and $k_{\text {in }}$ of eqn (20) ( $x$ : see Table 2a); ( : see Table 2b); ( $O$ : see Table 2c); $k$ represented by eqn (17) with the points $\times$ and $\mathbf{0} ; k_{\text {in }}$ represented by eqn (20) with the hightemperature limit of $k$ and points $(O$; see the text).

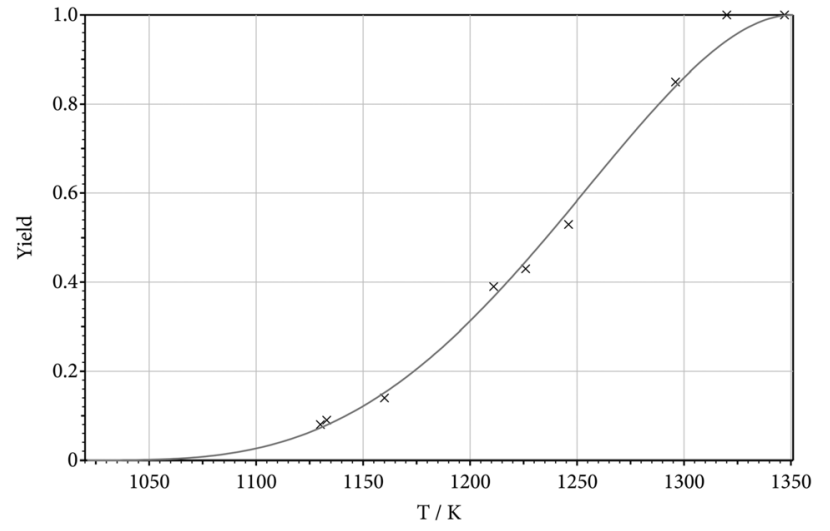

Fig. 7 Apparent final $\mathrm{CF}_{2}$ yields $Y=\left[\mathrm{CF}_{2}\right] /\left[\left(\mathrm{C}_{2} \mathrm{~F}_{5}\right)_{3} \mathrm{~N}\right]_{t=0}$ over the range of $1130-1450 \mathrm{~K}$ (representation by eqn (18)).

with the parameters $T_{\mathrm{e}}=1351 \mathrm{~K}, T_{0}=1020 \mathrm{~K}$, and fitted $T_{\mathrm{m}}=1295 \mathrm{~K}$. Alternatively, the formation of $\mathrm{CF}_{2}$ was characterized by its initial rate

$$
\left.\frac{\mathrm{d}\left[\mathrm{CF}_{2}\right]}{\mathrm{d} t}\right|_{t=0} \approx k_{\text {in }}(T)\left[\left(\mathrm{C}_{2} \mathrm{~F}_{5}\right)_{3} \mathrm{~N}\right]_{t=0}
$$

Values of $k_{\text {in }}(T)$ could also be derived for lower temperatures where a final stationary $\mathrm{CF}_{2}$ level could not be attained within the observation time. Fig. 6 and Table 2 include values of $k_{\text {in }}(T)$. In Arrhenius form they are represented by

$$
k_{\mathrm{in}}(T) \approx 1.4 \times 10^{17} \exp \left(-339 \mathrm{~kJ} \mathrm{~mol}^{-1} / R T\right) \mathrm{s}^{-1}
$$

when high-temperature limiting values of $k(T)$ near $1500 \mathrm{~K}$ are combined with the measured points of $k_{\text {in }}$ over the range of $1130-1250 \mathrm{~K}$ (one should note that the scatter of the values of $k_{\text {in }}$ is due to some uncertainties of the $\left(\mathrm{C}_{2} \mathrm{~F}_{5}\right)_{3} \mathrm{~N}$ concentration in the reaction mixtures, see eqn (19); this problem does not exist for the measurements of $k(T)$; thus eqn (20) is of qualitative importance only). The relation of the apparent $k(T), k_{\text {in }}(T)$, and $Y(T)$ to the dissociation pathways illustrated in Fig. 1 will be considered in Section 4.

It should be noted that experiments at higher temperatures (see Fig. 8), correspond to the dissociation of $\mathrm{CF}_{3}$ through reaction (3). The increase of the $\mathrm{CF}_{2}$ absorption behind the absorption step at the time of arrival of the reflected shock wave as shown in Fig. $8(T=1854 \mathrm{~K})$ leads to a value of the rate constant for reaction (3) of $k_{3} \approx 3.5 \times 10^{3} \mathrm{~s}^{-1}$. This is in perfect agreement with the result obtained from the $\mathrm{CF}_{3}$ dissociation study of ref. 12. While this confirms the overall mechanism, it limits the study of the later stages of $\left(\mathrm{C}_{2} \mathrm{~F}_{5}\right)_{3} \mathrm{~N}$ dissociation. One observes that the absorption step at the time of arrival of the reflected wave as shown in Fig. 8 corresponds to $Y \approx 2$ while finally $Y \approx 3$ is reached (as most clearly seen in the inset of Fig. 8). Apparently, $\mathrm{CF}_{3}$ dissociation and the slower steps of the $\left(\mathrm{C}_{2} \mathrm{~F}_{5}\right)_{3} \mathrm{~N}$ dissociation here are superimposed and could not be separated in the present experiments. Monitoring $\mathrm{CF}_{3}$ near $200 \mathrm{~nm}$ did not help, as the strong $\mathrm{CF}_{2}$ absorption at high temperatures extends from $248 \mathrm{~nm}$ down to $200 \mathrm{~nm}$ and is 


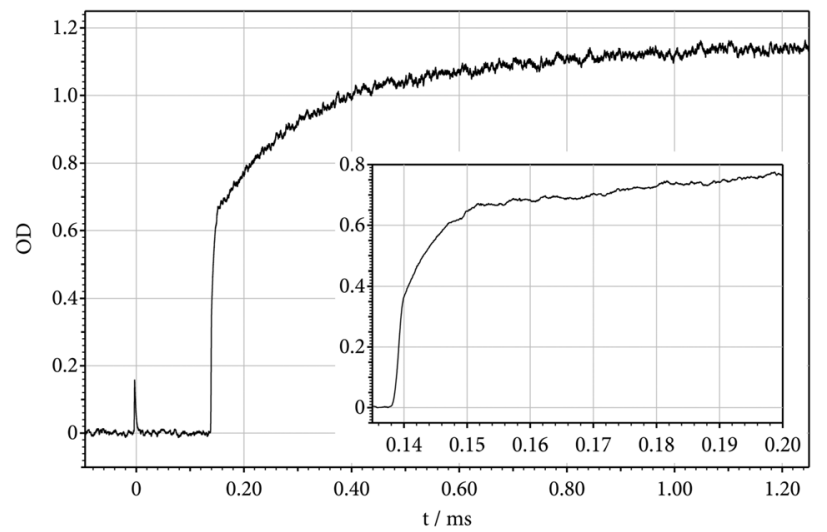

Fig. $8 \mathrm{CF}_{2}$ formation by the decomposition of $\mathrm{CF}_{3}$ produced during the decomposition of $\left(\mathrm{C}_{2} \mathrm{~F}_{5}\right)_{3} \mathrm{~N}$ (reflected shock wave at $1854 \mathrm{~K}$ and $[\mathrm{Ar}]=$ $2.9 \times 10^{-5} \mathrm{~mol} \mathrm{~cm}^{-3} ;\left[\left(\mathrm{C}_{2} \mathrm{~F}_{5}\right)_{3} \mathrm{~N}\right]_{t=0} /[\mathrm{Ar}]=528 \mathrm{ppm}$; the inset resolves $\mathrm{CF}_{2}$ formation during the late stages of $\left(\mathrm{C}_{2} \mathrm{~F}_{5}\right)_{3} \mathrm{~N}$ decomposition; for details see the text).

then superimposed on the $\mathrm{CF}_{3}$ absorption. In any case, in the intermediate temperature range between 1500 and $2000 \mathrm{~K} \mathrm{a} \mathrm{CF}_{2}$ yield of $Y=6$ was not reached. On the other hand, $Y$ approached unity in the range of 1300-1500 K.

\section{Discussion}

Although only limited experimental and theoretical information about the reaction network of Fig. 1 became available, a number of important conclusions could be drawn. The following pathways appear possible: (i) $\left(\mathrm{C}_{2} \mathrm{~F}_{5}\right)_{3} \mathrm{~N}$ dissociates in a sequence of $\mathrm{C}-\mathrm{N}$ bond ruptures (5)-(7) followed by fast dissociation (2) of the product $\mathrm{C}_{2} \mathrm{~F}_{5}$; (ii) $\left(\mathrm{C}_{2} \mathrm{~F}_{5}\right)_{3} \mathrm{~N}$ dissociates in a sequence of $\mathrm{C}-\mathrm{C}$ bond ruptures (8), (10), and (12), followed by $\mathrm{C}-\mathrm{N}$ bond ruptures (9), (11), and (13); (iii) two pathways (i) and (ii) occur in parallel with the possibility of cross-over at the stages of formation of $\left(\mathrm{C}_{2} \mathrm{~F}_{5}\right)_{2} \mathrm{~N}$ and $\left(\mathrm{C}_{2} \mathrm{~F}_{5}\right) \mathrm{N}$. At temperatures where the reactions of pathways (i)-(iii) are complete, and where $\mathrm{CF}_{3}$ dissociates through reaction (3) while reaction (4) is too slow to consume $\mathrm{CF}_{2}$, the overall $\mathrm{CF}_{2}$ yield $Y(T)$ should be 6 . This was indeed observed, but this does not allow one to distinguish between the pathways.

An exclusive mechanism (i) can be excluded for a number of reasons: although the enthalpies of the reaction steps slightly decrease from (5) to (7), rate constants $k_{5}, k_{6}$, and $k_{7}$ should be of similar magnitude. With a fast dissociation of $\mathrm{C}_{2} \mathrm{~F}_{5}$ this would then result in $Y=3$. A modelling of the kinetics indicates that the effective rate constant $k(T)$ in eqn (16) would correspond to about $k(T) \approx 2 k_{5}$. Furthermore, the derived value of $k(T)$ should correspond to a simple bond fission process with a preexponential factor of the order of $10^{15}-10^{17} \mathrm{~s}^{-1}$ while the activation energy should be of the order of the reaction enthalpy of reaction (5). These expectations are in disagreement with the experimental observations from Section 3.

Mechanism (ii) would have properties which are in closer agreement with the experiments. Particularly in its later stages, this mechanism would be governed by the alternation of low and high reaction barriers such that the reaction flux may "get stuck" at the level of $\left(\mathrm{C}_{2} \mathrm{~F}_{5}\right) \mathrm{N}+2 \mathrm{CF}_{3}+\mathrm{CF}_{2}$. This would explain $\mathrm{CF}_{2}$ yields $Y(T)$ near unity for experiments in the range of 1100-1500 K. However, the apparent rate constant $k$ should again correspond to a simple bond fission and $Y(T)$ should be close to unity even at the lowest temperatures of the present experiments. The latter two expectations are again in disagreement with the experimental observation.

It remains to inspect mechanism (iii) with the possibility of at least a partial cross-over between the two pathways (i) and (ii). The observation of a $\mathrm{CF}_{2}$ yield near unity over a wide temperature range suggests that the reaction gets stuck at the level of $\left(\mathrm{C}_{2} \mathrm{~F}_{5}\right) \mathrm{NCF}_{2}+\mathrm{CF}_{2}+2 \mathrm{CF}_{3}$, regardless of whether pathway (ii) or (i) with a cross-over at the level of $\left(\mathrm{C}_{2} \mathrm{~F}_{5}\right)_{2} \mathrm{~N}$ precedes the approach of the bottle-neck of reaction (10). Unfortunately, $\mathrm{CF}_{2}$ formation beyond the bottle-neck at higher temperatures in our experiments could not be distinguished from $\mathrm{CF}_{2}$ formation by decomposition of $\mathrm{CF}_{3}$ (see Section 3). However all evidence is for a slow completion of the reaction after reaching the bottle-neck. Finally, the properties of the apparent rate constant $k(T), k_{\text {in }}(T)$, and the decrease of $Y(T)$ to values below unity at low temperatures need to be rationalized. While the Arrhenius representation of $k(T)$ by eqn (17) corresponds more to a rigid-activated complex process, $k_{\text {in }}(T)$ in eqn (19) would appear consistent with a loose-activated complex of bond-fission type, like that expected for $k_{5}$ and/or $k_{8}$ (from reactions (5) and (8)).

It appears more difficult to explain the decrease of $Y(T)$ with decreasing temperature, while $k_{\text {in }}(T)$ corresponds to $k_{5}$ and/or $k_{8}$. An answer may come from speculations about the formation of the low-temperature final product $\left(\mathrm{C}_{4} \mathrm{~F}_{8}\right) \mathrm{NCF}_{3}$. If there is a branching of the reaction flux at the level of $\left(\mathrm{C}_{2} \mathrm{~F}_{5}\right)_{2} \mathrm{NCF}_{2}$, i.e. beyond the low-temperature rate-determining step (8) of pathway (ii), then the rate constant $k_{\mathrm{in}}(T)$ for $\mathrm{CF}_{2}$ formation would not be influenced while the $\mathrm{CF}_{2}$ yield would be. This branching by as yet unidentified rearrangement processes should involve rigid activated complexes with lower preexponential factors and activation energies than the competing bond fission (9). It would then win at lower temperatures and reduce here the $\mathrm{CF}_{2}$ yield of $Y(T)$, and this was observed in our experiments. Obviously, more work would be necessary to validate the given interpretation which would be able to reconcile the present high-temperature observations with the earlier low-temperature measurements of final products from ref. 6 .

\section{Conclusions}

The combination of quantum-chemical calculations and experiments monitoring the formation of product $\mathrm{CF}_{2}$ in $\left(\mathrm{C}_{2} \mathrm{~F}_{5}\right)_{3} \mathrm{~N}$ decomposition provided evidence for a sequence of $\mathrm{C}-\mathrm{N}$ and $\mathrm{C}-\mathrm{C}$ bond ruptures taking place simultaneously. Apparently, dissociation steps in the inner $\mathrm{CF}_{2}$-shell and in the outer $\mathrm{CF}_{3}$-shell occur in parallel and proceed as simple bond fission processes. The alternation of bond energies for the $\mathrm{C}-\mathrm{C}$ and $\mathrm{C}-\mathrm{N}$ bond rupture sequence of reactions (8)-(13) deserves particular attention. At temperatures that are sufficiently high for reactions (5)-(13) to occur, 
but low enough to keep $\mathrm{CF}_{2}$ undissociated, the observed overall yield of $6 \mathrm{CF}_{2}$ per consumed $\left(\mathrm{C}_{2} \mathrm{~F}_{5}\right)_{3} \mathrm{~N}$ confirms the kinetic analysis.

Details of the mechanism would not have been understood without the quantum-chemical calculations. As the decomposition of $\mathrm{C}_{2} \mathrm{~F}_{5}$ through reaction (2) forms an essential part of the mechanism and its rate was not well known before, the falloff curves of this important reaction also had to be modelled. Finally, the present experiments at temperatures above about $2000 \mathrm{~K}$ generate mixtures of $\mathrm{N}, \mathrm{F}$, and $\mathrm{CF}_{2}$ in a concentration ratio $1: 3: 6$. Recording absorption-time profiles for this mixture suggests contributions from $\mathrm{CF}_{2}$ and $\mathrm{CF}$, the latter not only arising from $\mathrm{CF}_{2}$ dissociation (4) but also from other, so far unidentified processes.

Finally, a branching of the mechanism at the level of $\left(\mathrm{C}_{2} \mathrm{~F}_{5}\right)_{2} \mathrm{NCF}_{2}$, on the one hand, may provide an explanation for the lowtemperature production of an end product like perfluoro- $N$ methylpyrrolidene, $\left(\mathrm{C}_{4} \mathrm{~F}_{8}\right) \mathrm{NCF}_{3}$, such as was observed earlier in ref. 6; on the other hand, this detail may also be responsible for the properties of the $\mathrm{CF}_{2}$ yields observed at the low-temperature end of the present experiments.

\section{Conflicts of interest}

There are no conflicts to declare.

\section{Acknowledgements}

Financial support from the Deutsche Forschungsgemeinschaft (Projekt TR69-20-3) is gratefully acknowledged. Open Access funding provided by the Max Planck Society.

\section{References}

1 H. Nakano and T. Kitazume, Organic Reactions Without an Organic Medium, Utilization of Perfluorotriethylamine as a Reaction Medium, Green Chem., 1999, 1, 21-22.

2 M. Gaensslen, U. Gross, H. Oberhammer and S. Rüdiger, Perfluorotriethylamine: An Amine with Unusual Structure and Reactivity, Angew. Chem., Int. Ed. Engl., 1992, 31, 1467-1468.

3 H. Bürger, H. Niepel, G. Pawelke and H. Oberhammer, Vibrational Spectra and Normal Coordinate Analysis of $\mathrm{CF}_{3}$ Compounds: Part XXVII. Perfluorotrimethylamine. Reinvestigation of the Molecular Structure by Electron Diffraction, J. Mol. Struct., 1979, 54, 159-174.

4 A. Dimitrov, H.-G. Mack, S. Rüdiger, K. Seppelt and H. Oberhammer, Structure and Conformation of Tris(2,2,2trifluoroethyl)amine, $\mathrm{N}\left(\mathrm{CH}_{2} \mathrm{CF}_{3}\right)_{3}$, in the Gaseous and Solid State, J. Phys. Chem., 1994, 98, 11401-11405.

5 J. B. Nielsen, P. Zylka, M. Kronberg, X. Zeng, K. D. Robinson, S. G. Bott, H. Zhang, J. L. Atwood, H. Oberhammer, H. Willner and J. S. Thrasher, Solid- and Gas-Phase Structures and Spectroscopic and Chemical Properties of Tris(pentafluorosulfanyl)amine, $\mathrm{N}\left(\mathrm{SF}_{5}\right)_{3}$ and Bis(pentafluorosulfanyl)aminyl Radical, • $\mathrm{N}\left(\mathrm{SF}_{5}\right)_{2}$, J. Mol. Struct., 2017, 1132, 11-19.
6 T. Yamamoto, A. Yasuhara, F. Shiraishi, K. Kaya and T. Abe, Thermal Decomposition of Halon Alternatives, Chemosphere, 1997, 35(3), 643-654.

7 V. P. Kolesov and M. P. Kozina, Thermochemistry of Organic and Organohalogen Compounds, Russ. Chem. Rev., 1986, 55, 912-928.

8 E. Goos, A. Burcat and B. Ruscic, Extended Third Millenium Ideal Gas and Condensed Phase Thermochemical Data Base for Combustion with Updates from Active Thermochemical Tables <ftp.technion.ac.il/pub/supported/aetdd/thermo dynamics $>$ Jan 2015 .

9 K. Li, E. M. Kennedy and B. Z. Dlogogorski, Experimental and Computational Studies of the Pyrolysis of $\mathrm{CBrF}_{3}$, and the Reaction of $\mathrm{CBrF}_{3}$ with $\mathrm{CH}_{4}$, Chem. Eng. Sci., 2000, 55, 4067-4078.

10 A. F. Ainagos, Mechanism and Kinetics of Pyrolysis of Perfluorohexane, Kinet. Catal., 1991, 32, 720-725.

11 N. K. Srinivasan, M.-C. Su, J. V. Michael, A. W. Jasper, S. J. Klippenstein and L. B. Harding, Thermal Decomposition of $\mathrm{CF}_{3}$ and the Reaction of $\mathrm{CF}_{2}+\mathrm{OH} \rightarrow \mathrm{CF}_{2} \mathrm{O}+\mathrm{H}$, J. Phys. Chem. A, 2008, 112, 31-37.

12 C. J. Cobos, A. E. Croce, K. Luther and J. Troe, Shock Wave Study of the Thermal Decomposition of $\mathrm{CF}_{3}$ and $\mathrm{CF}_{2}$ Radicals, J. Phys. Chem. A, 2010, 114, 4755-4761.

13 C. J. Cobos, A. E. Croce, K. Luther, L. Sölter, E. Tellbach and J. Troe, Experimental and Modeling Study of the Reaction $\mathrm{C}_{2} \mathrm{~F}_{4}(+\mathrm{M}) \leftrightarrow \mathrm{CF}_{2}+\mathrm{CF}_{2}(+\mathrm{M})$, J. Phys. Chem. A, 2013, 117, 11420-11429.

14 C. J. Cobos, G. Knight, L. Sölter, E. Tellbach and J. Troe, Kinetic and Spectroscopic Studies of the Reaction of $\mathrm{CF}_{2}$ with $\mathrm{H}_{2}$ in Shock Waves, J. Phys. Chem. A, 2017, 121, 7827-7834.

15 K. Glänzer, M. Maier and J. Troe, Shock-Wave Study of the High-Temperature UV Absorption and the Recombination of Trifluoromethyl Radicals, J. Phys. Chem., 1980, 84, 1681-1686.

16 C. J. Cobos, G. Knight, L. Sölter, E. Tellbach and J. Troe, Experimental and Modeling Study of the Multichannel Thermal Dissociation of $\mathrm{CH}_{3} \mathrm{~F}$ and $\mathrm{CH}_{2} \mathrm{~F}$, Phys. Chem. Chem. Phys., 2018, 20, 2627-2636.

17 M. J. Frisch, et al., Revision A.02, Gaussian Inc., Wallingford, CT, USA, 2009.

18 A. D. Becke, Densitiy-Functional Exchange-Energy Approximation with Correct Asymptotic Behavior, Phys. Rev. A: At., Mol., Opt. Phys., 1988, 38, 3098-3100.

19 C. Lee, W. Yang and R. G. Parr, Development of the Colle-Salvetti Correlation-Energy Formula into a Functional of the Electron Density, Phys. Rev. B: Condens. Matter Mater. Phys., 1988, 37, 785-789.

20 Y. Zhao and D. G. Truhlar, The M06 Suite of Density Functionals for Main Group Thermochemistry, Thermochemical Kinetics, Noncovalent Interactions, Excited States, and Transition Elements: Two New Functionals and Systematic Testing of Four M06-Class Functionals and 12 Other Functionals, Theor. Chem. Acc., 2008, 120, 215-241.

21 A. D. Boese and J. M. Martin, Development of Density Functionals for Thermochemical Kinetics, J. Chem. Phys., 2004, 121, 3405-3416. 
22 J.-D. Chai and M. Head-Gordon, Long-Range Corrected Hybrid Density Functionals with Damped Atom-Atom Dispersion Corrections, Phys. Chem. Chem. Phys., 2008, 10, 6615-6620.

23 J. A. Montgomery, M. J. Frisch, J. W. Ochterski and G. A. Petersson, A Complete Basis Set Model Chemistry. VI. Use of Density Functional Geometries and Frequencies, J. Chem. Phys., 1999, 110, 2822-2827.

24 L. A. Curtiss, P. C. Redfern and K. Raghavachari, Gaussian-4 Theory, J. Chem. Phys., 2007, 126, 084108.
25 NIST Kinetics Database 17, Version 7.0 (Web Version), Release 1.6.8, Data Version 2015.09.

26 Y. Li, X. Zhang, S. Xiao, Q. Chen, J. Tang, D. Chen and D. Wang, Decomposition Properties of $\mathrm{C}_{4} \mathrm{~F}_{7} \mathrm{~N} / \mathrm{N}_{2}$ Gas Mixture: An Environmentally Friendly Gas to Replace $\mathrm{SF}_{6}$, Ind. Eng. Chem. Res., 2018, 57, 5173-5182.

27 X. Yin, J. Goudriaan, E. A. Latinga, J. Vos and H. J. Spiertz, A Flexible Sigmoid Function of Determinate Growth, Ann. Bot., 2003, 91, 361-371. 